\title{
A state parameter for sands
}

\author{
K. BEEN and M. G. JEFFERIES (1985). Géotechnique 35, No. 2, 99-112
}

\author{
Mr J. A. Sladen and Mr J. Krahn, EBA Engineer- \\ ing Consultants Ltd, and $\mathrm{Mr}$ R. D. Hollander, \\ Dames and Moore
}

The concept of a 'state parameter' as described by Been and Jefferies is not new and its application in soil mechanics has not been restricted historically to the study of sands. Furthermore the concept has not been applied only to axisymmetric compression tests, as they claimed, but also to plane strain conditions.

On the basis of both theoretical and experimental considerations, Roscoe \& Poorooshasb (1963) concluded that any two samples of a given soil when subjected to geometrically similar stress paths will have the same strains provided that the difference between the initial void ratio and the void ratio at the critical state at the same normal stress is the same for each sample. This similarity principle has been shown to be valid for many real and artificial soils and forms the basis of a widely used method of normalizing test data which has been described in detail in the textbook by Atkinson \& Bransby (1978). Indeed this principle could be said to be a cornerstone of critical state soil mechanics and it is surprising in view of the obvious similarities to the state parameter concept that the Authors do not make direct reference to it.

As stated, the principle has been applied to both axial symmetry and plane strain conditions. For axially symmetric conditions Roscoe and Poorooshasb use the first invariant of stress as the appropriate 'normal' stress parameter, as do the Authors. The only difference between the requirement for similarity of behaviour suggested by Roscoe and Poorooshasb and the state parameter proposed by the Authors is that Roscoe and Poorooshasb relate soil state to the critical state line whereas the Authors use the 'steady state' line. It will be argued below that this difference is merely one of semantics, as for sands the critical and 'steady' states are for practical purposes one and the same.

The 'steady state of deformation' has been defined as follows (Poulos, 1981).

'The steady state of deformation for any mass of particles is that state in which the mass is continuously deforming at constant volume, constant normal effective stress, constant shear stress, and constant velocity. The steady state of deformation is achieved only after all particle orientation has reached a statistically steady state condition and after all particle breakage, if any, is complete, so that the shear stress needed to continue deformation and the velocity of deformation remain constant.'

A comparison of this definition of steady state with that of the critical state, which has been defined as the state in which the soil 'continues to deform at constant stress and constant void ratio' (Roscoe, Schofield \& Wroth, 1958) clearly indicates that the concepts of critical and steady states are very similar. Castro, Enos, France \& Poulos (1982) have suggested that, while for clays the steady state is more analogous to a residual than to a critical state, for sands the difference is not practically significant.

This distinction between sands and clays is supported by the work of Lupini, who has shown that, while in clays post-peak loss of strength in drained conditions can be attributed to a combination of particle reorientation and dilation, in granular soils dilation is the dominant effect and particle reorientation is not significant. This being the case, it might be expected that if a difference exists between critical and steady states it is related to the 'constant velocity' requirement in the definition of steady state. If the location of the steady state line were a function of the velocity of deformation, however, then variations could be expected in steady state parameters determined from tests performed at different rates of strain, particularly between tests conducted under stresscontrolled and strain-controlled conditions: this is not the case (Castro et al., 1982). Further data to support the supposition that the behaviour of sand is largely independent of strain rate have been presented by Schimming, Haas \& Saxe (1966) and Hungr \& Morgenstern (1984).

The Writers disagree with the Authors' statement the question of whether the critical state and the steady state are the same or different does not affect the state parameter concept'. Accepting that they are the same, the Authors' data can be seen as reaffirmation of the validity of a basic principle of critical state soil mechanics, which was first formally expounded more than 20 years ago, and the Authors' correlations between state parameter and various geotechnical behaviours can claim the support of the theoretical and 
experimental data that can be found in the extensive literature on the subject. If, however, they were different then the Authors' correlations would be merely empirically observed trends based on a relatively small body of data with no theoretical basis, the more general applicability of which would be unknown.

The Authors' contention that 'critical state soil mechanics relies on the existence and measurement of a single virgin consolidation line' and their implication that this precludes the application of critical state soil mechanics to the study of sand are incorrect. Critical state soil mechanics principles, including that of Roscoe and Poorooshasb, have been used successfully by many workers in the study of sand behaviour (e.g. Cole, 1967; Stroud, 1971). Furthermore, the application of critical state soil mechanics to sensitive soils, such as very loose sands, whose in situ void ratio can be very much higher than the critical state void ratio, has been discussed in the textbook by Bolton (1979).

\section{REFERENCES}

Atkinson, J. H. \& Bransby, P. L. (1978). The mechanics of soils, an introduction to critical state soil mechanics. London: McGraw-Hill.

Bolton, M. (1979). A guide to soil mechanics. New York: MacMillan.

Castro, G., Enos, J. L., France, J. W. \& Poulos, S. J. (1982). Liquefaction induced by cyclic loading. Report to National Science Foundation, Washington, NSF/ CEE-82018.

Cole, E. R. (1967). The behaviour of soils in the simple shear apparatus. $\mathrm{PhD}$ thesis, University of Cambridge.

Hungr, O. \& Morgenstern, N. R. (1984). Experiments on the flow behaviour of granular materials at high velocity in an open channel. Géotechnique $\mathbf{3 4}$, No. 3 , $405-413$.

Poulos, S. J. (1981). The steady state of deformation. $J$. Geotech. Engng Div. Am. Soc. Civ. Engrs 107, GT5, $553-562$.

Roscoe, K. H. \& Poorooshasb (1963). A fundamental principle of similarity in model tests for earth pressure problems. Proc. 2nd Asian Conf. Soil Mech. 1, 134-140.

Roscoe, K. H., Schofield, A. N. \& Wroth, C. P. (1958). On the yielding of soils. Geotechnique 8, No. 1, 22-53.

Schimming, B. B., Haas, H. J. \& Saxe, H. C. (1966). Study of dynamic and static friction failure envelopes. J. Soil Mech. Fdn Engng Div. Am. Soc. (iv. Engrs 92, SM2, 105-124.

Stroud, M. A. (1971). The behaviour of sand at low stress levels in the simple shear apparatus. PhD thesis, University of Cambridge.

Dr C. C. Hird and Mr F. Hassona, University of Sheffield

In their Paper the Authors propose the use of a physical state parameter, which combines the influence of void ratio and stress, to characterize the behaviour of sands in triaxial tests. The state parameter is referenced to a steady state which is said to exist at, or towards, the end of a consolidated undrained stress-controlled test in which liquefaction occurs. At the steady state the sand is supposed to deform under conditions of constant stress, void ratio and velocity (strain rate). The behaviour of the sand is correlated with the distance of its initial state from a locus of steady states in $e-I_{1}$ space.

Attention is drawn in the Paper to similarities between the Authors' approach and that of critical state soil mechanics, but the Authors claim that it is much easier, experimentally, to determine the steady state line (SSL) than the critical state line (CSL). This is a questionable claim in the view of the Writers. In the definition of the critical state (Schofield \& Wroth, 1968), there is reference to neither magnitude nor constancy of strain rate, but critical state soil mechanics is founded on data obtained in conventional, relatively slow tests. If loose specimens of sand are subjected to undrained strain-controlled loading, a very similar pattern of bchaviour may be observed to that seen in stress-controlled tests; in Fig. 1 the results of typical tests on Leighton Buzzard sand are compared. The steady states reached at the end of the strain-controlled tests may be justly termed critical states and used to define a CSL. In theory this CSL should be identical with that obtained from other types of test performed at modest strain rates, although this may be difficult to demonstrate. As shown by Casagrande (1975), and reported by Green \& Ferguson (1971), the two lines, the SSL from the stress-controlled tests and the CSL from the strain-controlled tests, are likely to be parallel in $e-I_{1}$ space. The reason that they do not coincide is that the velocity of deformation is so very much faster on the SSL, this being associated with the formation of a (dynamic) flow structure. Whether the position of the SSL varies with the strain rate during liquefaction under stresscontrolled loading is not known but it may do so, i.e. the SSL may not be unique. If this were the case, the results obtained in a laboratory test would depend on the nature of the loading system and its ability to accelerate the specimen. For example, the capability of a dead weight system would be reduced by applying the load through a lever arm. In a liquefaction test the definition of the steady state also presents a problem. In our experience, at no stage of the deformation during liquefaction is the velocity constant. The test specimen and loading system continue to accelerate until an arresting system comes into operation. Therefore, in practice, 

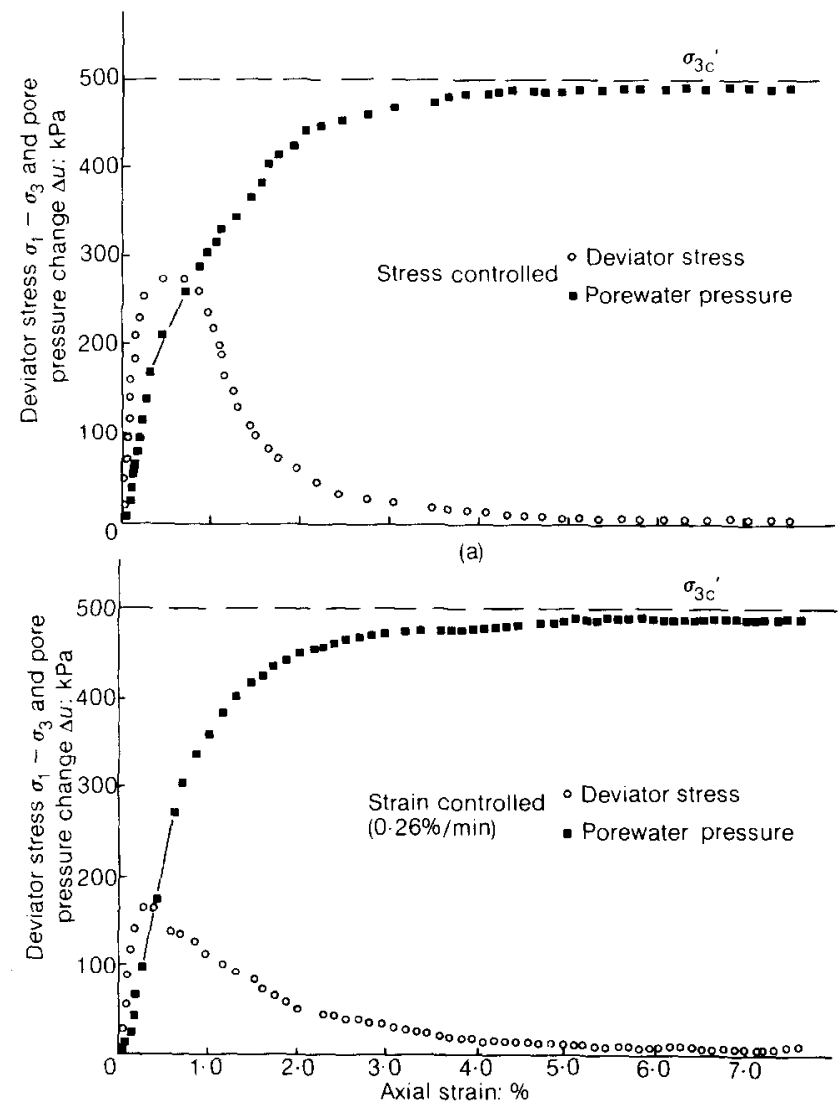

(b)

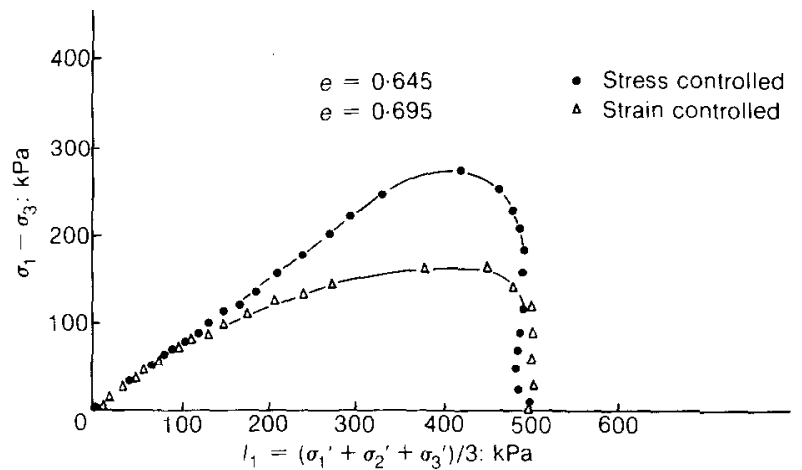

(c)

Fig. 1. Results of stress-controlled and strain-controlled consolidated isotropically undrained tests on Leighton Buzzard sand

judgement has to be used to identify a stage in the test when stresses, at least, have become approximately constant. However, it is sometimes questionable whether stresses, including pore pressures, are truly uniform and are being reliably measured in triaxial specimens which are deforming rapidly to axial strains of around $20 \%$.
In our opinion the behaviour of sands at slow strain rates, for example in drained tests, should be referred to the CSL. However, for liquefaction behaviour the use of the SSL is more appropriate, notwithstanding the difficulties in its determination referred to earlier. In support of the Authors, we present our own data for Leighton 


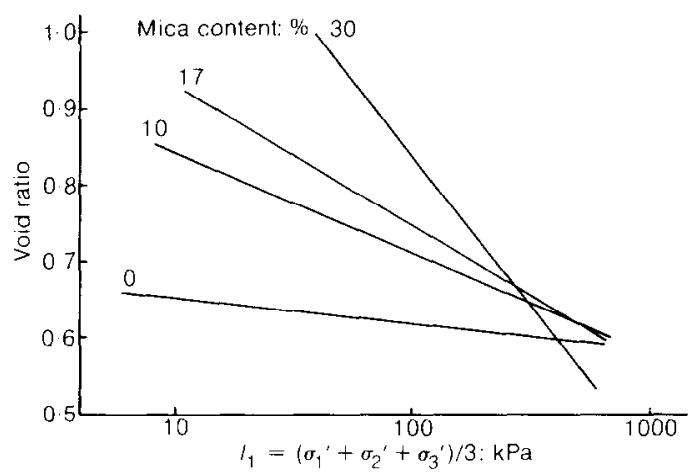

Fig. 2. SSLs for Leighton Buzzard sand with various mica contents

Buzzard sand, both in a pure form and mixed with various percentages of mica, in Figs $2-4$ and Table 1 . The test procedures were generally similar to those adopted by the Authors except that carbon dioxide was not used to improve the saturation of the specimens. The SSLs for these micaceous soils are shown in Fig. 2; as the mica content, and hence the compressibility, of the

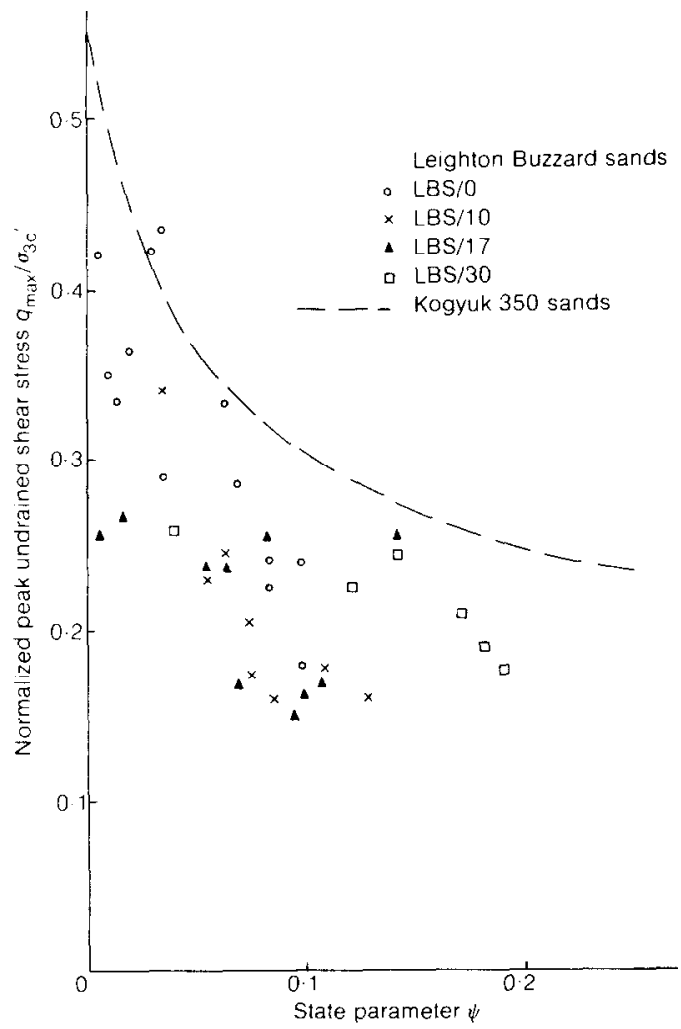

Fig. 3. Peak undrained shear strength as a function of the state parameter $\psi$ for Leighton Buzzard sands

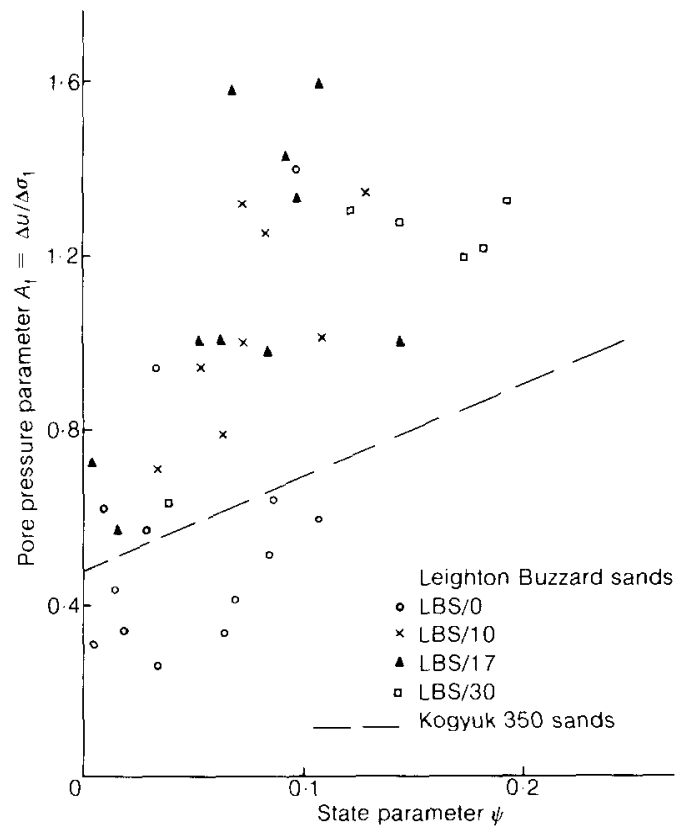

Fig. 4. Pore pressure parameter $A_{f}$ as a function of the state parameter $\psi$ for Leighton Buzzard sands

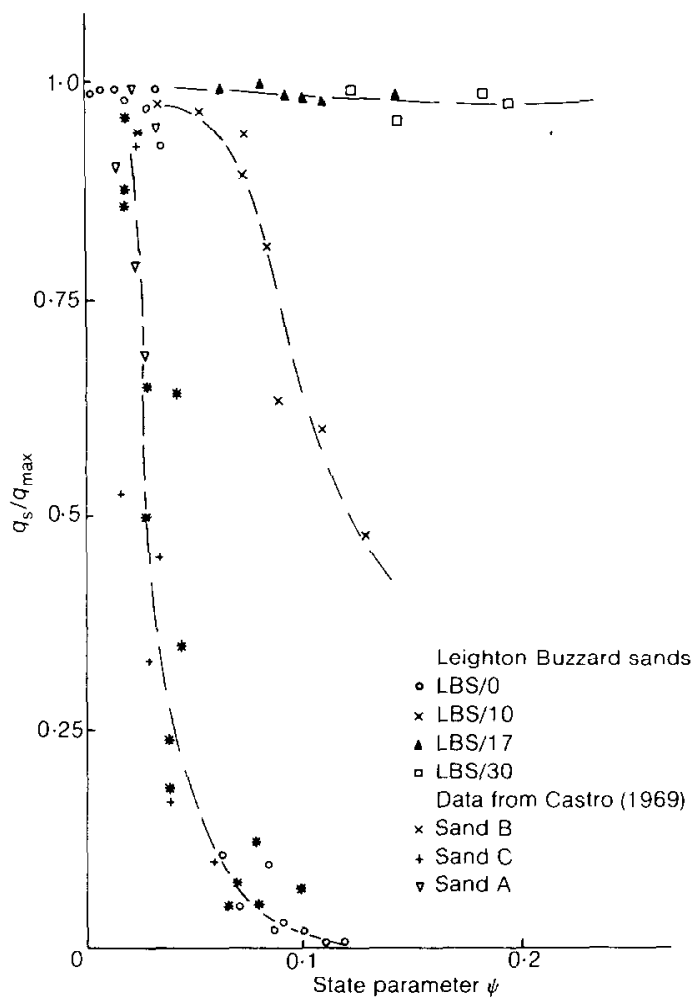

Fig. 5. Ratio $q_{\mathrm{s}} / q_{\max }$ as a function of the state parameter $\psi$ 
Table 1. Material properties of mixtures of Leighton Buzzard sand and mica

\begin{tabular}{l|l|l|l|l}
\hline & LBS/0 & LBS/10 & LBS/17 & LBS/30 \\
\hline Mica content: \% & 0 & 10 & 17 & 30 \\
Median grain size $D_{50}: \mathrm{mm}$ & 0.5 & 0.43 & 0.8 & 0.7 \\
Uniformity coefficient $D_{60} / D_{10}$ & 1.41 & 1.38 & 1.70 & 1.78 \\
Maximum void ratio $e_{\max }$ & 0.79 & 1.07 & 1.32 & 1.789 \\
Minimum void ratio $e_{\min }$ & 0.515 & 0.591 & 0.615 & 0.823 \\
$e_{\mathrm{ss}}$ at $I_{1}=10 \mathrm{kPa}$ & 0.65 & 0.845 & 0.93 & 1.225 \\
\hline
\end{tabular}

material increases, so the SSL steepens. In Figs 3 and 4 the normalized undrained shear strength $q_{\text {max }} / \sigma_{3 \mathrm{c}}{ }^{\prime}$ and pore pressure parameter $A_{f}$ are plotted respectively against the state parameter $\psi$, together with the mean relationships shown in Figs 9 and 10 of the Paper. It is evident that correlations must be established on an individual basis for each material tested, unless some way of normalizing $\psi$ can be found. The Writers have attempted to normalize $\psi$ by dividing it by $e_{\max }-e_{\min }$ but this does not produce any unification of the available data.

The parameters $q_{\max } / \sigma_{3 \mathrm{c}}{ }^{\prime}$ and $A_{\mathrm{f}}$ rclate to the high points on the stress paths shown in Fig. 8 of the Paper. From the liquefaction viewpoint, what is of more concern is the reduction in strength and the increase in pore pressure which occur thereafter. If the severity of liquefaction is expressed by the ratio $q_{\mathrm{s}} / q_{\max }$, where $q_{\mathrm{s}}$ is the shear stress at the steady state, and plotted against $\psi$, Fig. 5, the sands containing most mica are seen to be least susceptible to severe liquefaction. Indeed the sand containing $30 \%$ mica flows rather than liquefies and the deformations are relatively slow. Data from Castro (1969) are included in Fig. 5 to reinforce the data for Leighton Buzzard sand and it would be interesting to see the Authors' data also plotted in this way.

Alternatively, if the scverity of liquefaction is thought of in terms of a reduction in mean normal effective stress $I_{1}$ and defined as $\left(I_{1}\right)_{s} /\left(I_{1}\right)_{\mathrm{c}}$, where the subscripts $\mathrm{s}$ and $\mathrm{c}$ refer to the steady state and the initial state respectively, the severity is related to (positive values of) the state parameter by

$$
\left(I_{1}\right)_{\mathrm{s}} /\left(I_{1}\right)_{\mathrm{c}}=\exp (-\psi / \lambda)
$$

\section{REFERENCES}

Casagrande, A. (1975). Liquefaction and cyclic deformation of sands, a critical review. Proc. 5th PanAm. Conf. Soil Mech. Fdn Engng, Buenos Aires 5, 80-133.

Castro, G. (1969). Liquefaction of sands. PhD thesis, Harvard University.

Green, P. A. \& Ferguson, P. A. S. (1971). On liquefaction phenomena, by Professor A. Casagrande: report of lecture. Géotechnique 21, No. 3, 197-202.

Schofield, A. N. \& Wroth, C. P. (1968). Critical state soil mechanics. London: McGraw-Hill.

\section{Authors' reply}

Sladen, Hollander and Krahn raise the issue of the originality, origin and application of the 'state parameter'. Since these Discussers appear to misunderstand the nature and utility of the state parameter, perhaps the concept was not clarified adequately in the Paper.

Engineering and construction using sand fills necessarily must acknowledge that the mean grain size and silt content of the fill will vary, sometimes considerably, even on the most wellcontrolled jobs with well-surveyed borrow pits. The design of sand fills requires the characterization of the fill and its properties, such characterization recognizing the material variability. Relative density, which incorporates differences in material type, is commonly used by the profession as the characterizing parameter. However, the Paper showed that relative density is inadequate for characterizing sand behaviour in the very simple case of laboratory triaxial tests on samples of constant median grain size but varying silt content. In contrast, the Paper also showed that the state parameter approach worked well as a characterizing parameter irrespective of silt content for one sand (Kogyuk $350 \mu \mathrm{m}$ ). Further, the $\phi^{\prime}$ data presented for several sands implied that the state parameter uniquely characterizes sand behaviour irrespective of mean grain size and mineralogy. The state parameter approach also captures the influence of confining stress. The Paper proposed, therefore, that the state parameter was generally applicable to the engineering of sandfills in that it allowed a sandfill to be characterized while skirting the issues of grain size, silt content, mineralogy and confining stress variation (at least for the broad class of subrounded to subangular sands as discussed later).

The state parameter provides a parameter that uniquely characterizes some key engineering behaviours of sand in a single number independently of material type. Critical state soil mechanics, however, is one of several intellectual frameworks for examining the stress-strain behaviour of soils in general, the parameters used taking on different values for each soil examined. Thus state parameter provides limited behavioural information but allows independence from 
sand type whereas critical state theory provides detail but with parameters that differ for each soil. The definition of the critical (or steady) state is nevertheless the starting point for both approaches.

Both Discussers have raised the issue of critical state versus steady state. Without attempting to resolve the question, some important points may be noted. From a theoretical viewpoint a distinction cannot be made between the critical and steady states. Both are states of shearing at constant volume and stress conditions, which also implies a state of 'limiting' shear stress. A state of limiting shear stress defines a suitable reference state for particulate media. The steady state is proposed because it is easier to measure (and more repeatable) than the critical state.

There is conflicting evidence in the literature, and in the opinions of the two groups of Discussers, regarding rate effects on the determination of the ultimate state of a sand. We consider that undrained triaxial tests on loose sands are more appropriate than, for example, drained triaxial tests are on dense sands. Loose sands are relatively homogeneous at failure, whereas dense sands tend to develop shear planes. Undrained test samples are driven towards the ultimate state by pore pressure changes and small strains are capable of producing very large pressure changes. In contrast, drained test samples rely on volume changes to reach the ultimate state, and large shear strains are generally required. Drained triaxial tests gencrally do not reach a well-dcfincd, well-mcasured ultimate state and indeed some characteristics of the test equipment preclude this. Hird and Hassona rightly draw attention to the difficulties associated with carrying out stress-controlled 'liquefaction' tests. However, if due attention is paid to transducer response time and the electronic technology used, then the measurements are more reliable than the Discussers imply. For example, there is no difficulty in defining the steady state on Fig. 6 of the Paper. It may also be noted that stress-controlled loading is not entirely arbitrary unless a lever system is used. The load acting on the sample during liquefaction is controlled by the maximum shear stress, which in turn is a function of the initial state of the sample. A reasonable 'standard' test could therefore be developed, even if gravity varied! Standardization is all that is required for the application of the state parameter approach.

Much of the discussion put forward by Sladen, Hollander and Krahn depends on the similarity principle and their contention that such a principle applies to sands. We regard these views as simplistic and fundamentally unsound.
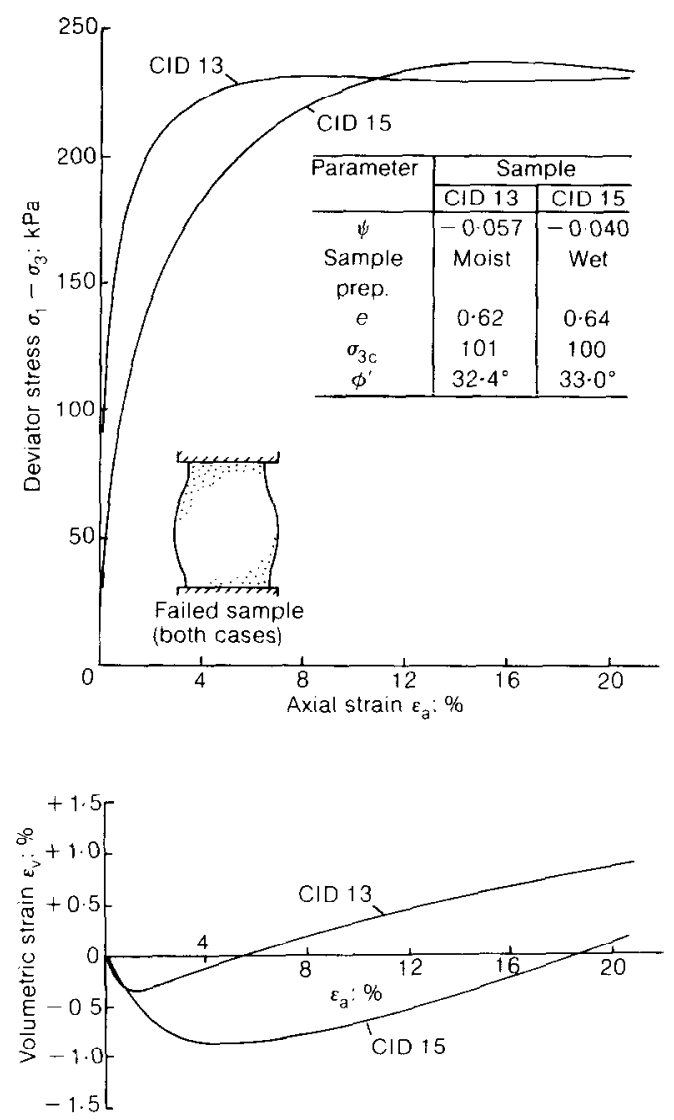

Fig. 6. Effect of sample preparation on constitutive behaviour of sand (drained tests)

Figure 6 shows data from the Kogyuk sand testing programme to illustrate this point. Two samples were prepared by different methods to essentially identical densities and subjected to equal confining stresses (similar values of state parameter). The sample preparation methods used were describer in the Paper and are classified as moist tamping and pluviation. Neither the deviator stress curves nor the volumetric strain curves are similar. In particular, the volumetric strain behaviour is substantially different. Despite this, both the peak and ultimate shear stresses were very similar. Consequently $\phi^{\prime}$ values are also similar. Interestingly, maximum dilation rates were also similar in each case.

Figure 6 is shown to make the point that state is not the only controlling parameter. The changes in sand behaviour induced by changes in preparation method are ascribed to fabric. Different preparation methods produce different sand fabrics and these fabric differences produce different behaviours. This has been shown in a more 


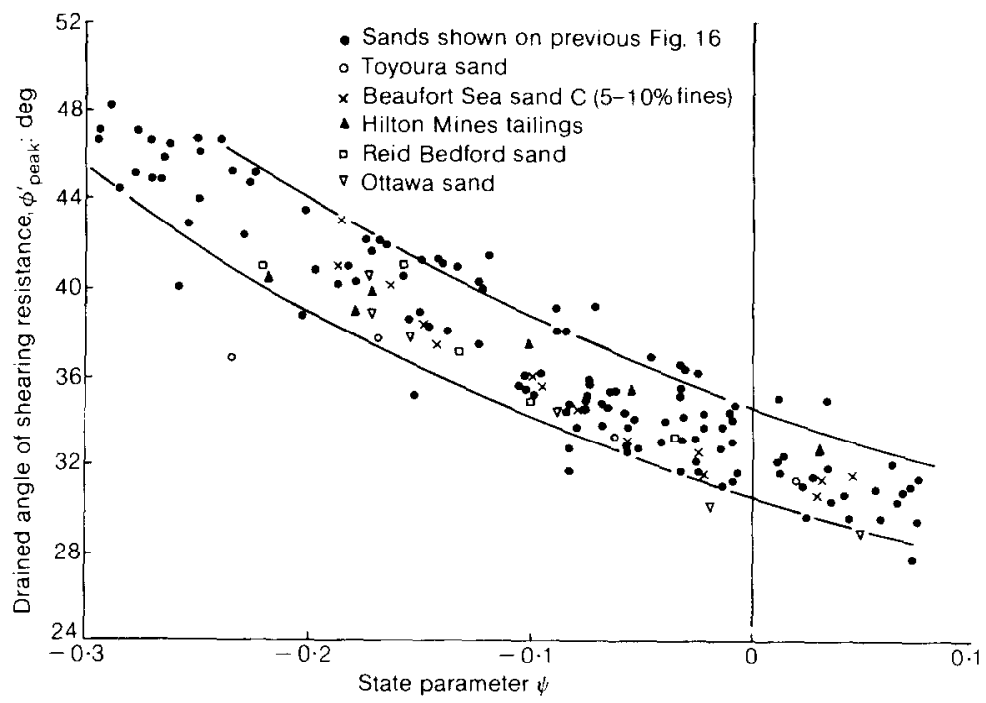

Fig. 7. Angle of shearing resistance for several sands from the Arctic, Europe, North and South America (revised Fig. 16, with additional data)

elegant and satisfactory way by Arthur \& Menzies (1972).

Arthur \& Menzies (1972) clearly showed the importance of initial fabric to sand behaviour, differences in excess of $200 \%$ in axial strains being encountered at equal stress ratios for a sand with a constant state parameter. Further, they found a typical variation of $2^{\circ}$ in peak friction angle as a function of sand fabric. Similar direct effects of fabric have been reported by Oda (1972a, 1972b), Oda, Konishi \& Nemat-Nasser (1980) and Miura, Toki \& Tanizawa (1984). The influence of fabric on stress distribution in a granular material has been demonstrated theoretically by Rothenburg, Jefferies \& Matyas (1985).

We contend that the experimental evidence on the effect of fabric is conclusive. This evidence has direct bearing on two points raised by Sladen, Hollander and Krahn. Firstly, it denies the similarity principle. Secondly, it contradicts their contention that fabric changes ('particle reorientation') during shear are unimportant.

Sladen, Hollander and Krahn do have an interesting point with regard to where the state parameter fits in an overall framework of sand characterization. They plainly view its place as purely part of critical state soil mechanics. We consider this an incorrect view.

The state parameter has a number of features, each of which belongs in different models. The origin behind state parameter was critical state soil mechanics, as noted in the Paper. However, the state parameter is then used in an 'endochronic' manner (Valanis, 1971) but this use of state is similar to Rowe's 'stress-dilatancy' theory as discussed in the Paper. Rowe (1971) also noted that the dilatancy component depended on both void ratio and mean stress. We stated in the Paper that fabric should be regarded as a second characteristic of equal importance to state and, although we did not discuss much with regard to fabric in the Paper, our views are summarized earlier in this reply. We regard state parameter as part of the particulate school of sand characterization.

Sladen, Hollander and Krahn also suggest that the use of the steady state removes the theoretical underpinning of critical state theory and reduces state parameter to 'merely empirically observed trends based on a relatively small body of data'. As outlined above, the state parameter is not part of critical state soil mechanics, but rather an endochronic extension of it. Thus, even if the steady state and the critical state are the same (and we consider they are), generalized critical state theory would provide no assurances on the validity of the state parameter approach. Further, the influence of fabric referred to earlier would certainly have to raise doubts if critical state soil mechanics were relied on. However, the implication made by Sladen, Hollander and Krahn regarding the desirability of having a theoretical underpinning to parameters used in practice is most certainly correct, and we are in total agreement.

Theoretical developments have occurred in the behaviour of particulate media which are not related to critical state theories. A generalized 


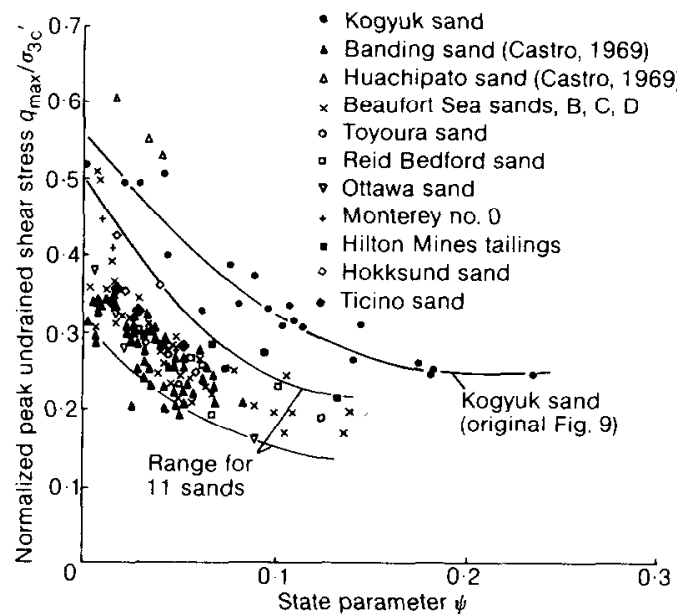

Fig. 8. Undrained strength ratio for several sands as a function of the state parameter

theory of particulate media has been developed at the University of Waterloo based on the original formulation of Rothenburg (1980) with necessary assumptions being numerically verified by discrete element modelling (Bathurst, 1985). State parameter is one parameter of this theory while fabric is the other. Some aspects of this work have been published (Rothenburg \& Selvadurai, 1981; Rothenburg et al., 1985) and a complete exposition will be shortly forthcoming.

The presentation of state parameter in the Paper was essentially empirical. We must remark that the data base for state parameter-sand behaviour relations presented in the Paper is wider than Sladen, Hollander and Krahn imply. For example, Fig. 16 of the Paper shows independent data from 13 sands. Testing of various sands has continued since publication of the Paper and there are now 20 sands in the data base, which allows a revised Fig. 16 (Fig. 7). It should be noted that the recent data all fit within the previously presented trend lines. Fig. 7 includes sands with mean grain sizes varying from $110 \mu \mathrm{m}$ to $650 \mu \mathrm{m}$ and silt contents varying from $0 \%$ to $12 \%$. Yet, the same relationship holds, on average (i.e. excluding fabric effects), between $\phi^{\prime}$ and $\psi$. This material independence is the principal claim to originality for $\psi$, and its utility.

It will be appreciated in the light of this that the observation by Hird and Hassona regarding individual correlations being required for normalized undrained strength and $\psi$ is by far the most serious of the various points raised by the Discussers. There are actually two issues raised by Hird and Hassona. The first is how well the state parameter works in undrained loading. The second is possible limits of applicability of the state parameter.

Plastic volumetric strains are particularly important during undrained loading since it is these that drive the excess pore pressures, such pore pressures affecting both the undrained strength and the pore pressure ratio at failure. Earlier in this reply we outlined the importance of fabric to the constitutive behaviour of sand. It is possible that we have overstated the utility of the state parameter for undrained loading. However, testing of other sands since the Paper was published has shown that Kogyuk sand is anomalously strong (which may in part explain its successful use in undensified, hydraulically placed sand fills subjected to dynamic loading). Fig. 8 shows a revised plot of normalized undrained strength for various sands. The trend from Fig. 8 is compared with the data of Hird and Hassona in Fig. 9. It can be seen that the Leighton Buzzard sand is broadly comparable with several other sands while Kogyuk sand is anomalous. The fact that several sands plot in the same band denies the need for individually developed correlations, but data are clearly required to verify that a sand is behaving as expected. This level of data will be available from the undrained tests required to define the steady state line which is the starting point for the application of the state parameter.

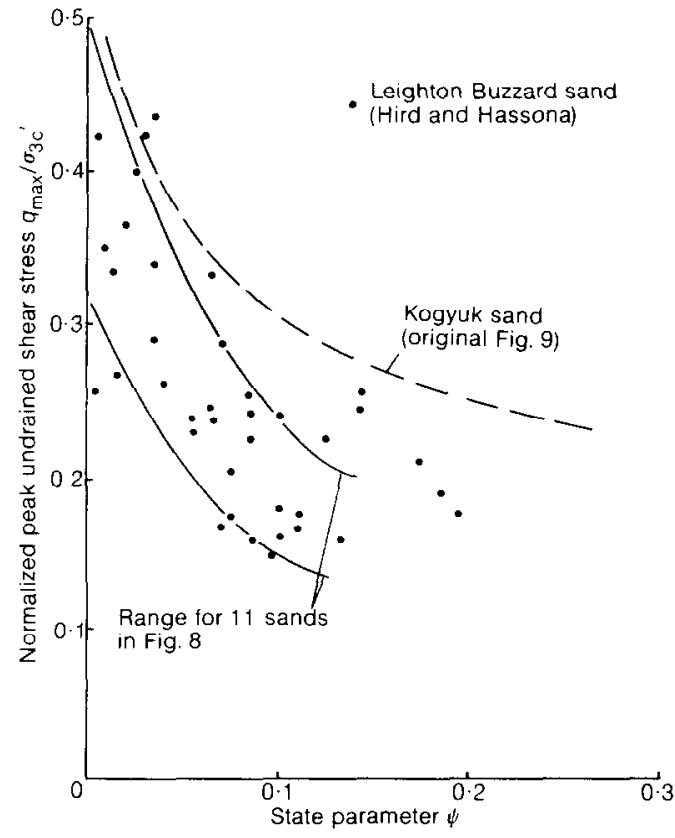

Fig. 9. Comparison of the general trend in undrained strength ratio with the data of Hird and Hassona 


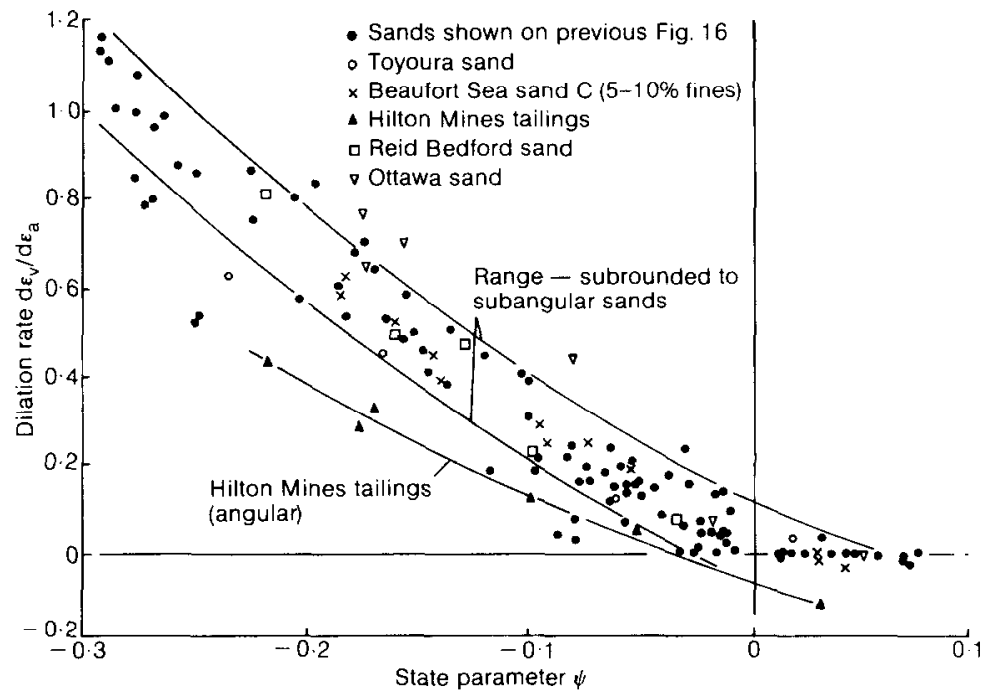

Fig. 10. Peak dilation rate as a function of state parameter for several sands

Hird and Hassona's undrained data for Leighton Buzzard sand is an intercsting contribution. We inferred in the Paper that the state parameter approach is mineralogy independent because of the different sands fitting the trend shown on Fig. 16 , an indirect conclusion. However, the data presented by Hird and Hassona are a direct demonstration of the independence of state parameter from mineralogy since they varied the mineralogy and still recovered the general trend in undrained strength. We encourage them to complete their test programme (including some drained tests) and to publish the results.

When the Paper was written the data available to us implied that the state parameter was uniquely applicable to determine an average $\phi^{\prime}$ or dilation rate for all sands. In fact, the data available came entirely from subrounded to subangular sands so that this view was not necessarily supported. Recently some angular, tailings sands have been tested and give different behaviours with $\psi$, although with the same trends. This is illustrated in Fig. 10 for one such tailings sand in terms of dilation rate. Clearly, some form of normalization of $\psi$ is required if it is to be returned to the concept of universal applicability irrespective of sand grading, type or mineralogy.

Hird and Hassona note that normalizing $\psi$ by $e_{\max }-e_{\min }$ produces no useful unification. A similar pressure-normalized relative density approach (called relative dilatancy index $I_{R}$ ) has recently been proposed by Bolton (1984). We note that the use of maximum and minimum densities introduces many of the problems of relative density that we sought to avoid originally. There is a more rational normalization availablc, however.

When considering the behaviour of particulate media it is obvious that the deformation allowed by the boundaries of the sand must accommodate the dilation of the material and that if dilation occurs at a fast enough rate (compared with what is allowed by the boundaries) then the particles may become kinematically constrained - in effect locked up. Under such a condition, the material can no longer be regarded as particulate and the theoretical approach becomes invalid. Given the relationship between dilation rate and $\psi$ it appears that $\psi$ itself may define its own end point of applicability, which we call $\psi$ (the lower bound on $\psi$ ). The true, material-independent normalizing parameter would then be

$$
\psi^{*}=\psi / \psi
$$

An exposition of this concept must await a future paper. For the moment we observe that the relations of sand engineering parameters to $\psi$ presented in the Paper are only applicable to subrounded and subangular sands.

A final aspect of state parameter which was not sufficiently emphasized in the Paper is its precision and limits of application. The use of the state parameter along the lines advocated by the Authors involves the acceptance that fabric effects are not important for the purpose at hand. While this may be true for, say, a drained stability analysis it is unlikely to be true for, say, a cyclic mobility assessment (where fabric dominates). The relative importance of fabric and state for the 
situation at hand must be understood before the state parameter approach can be properly applied.

\section{REFERENCES}

Arthur, J. R. F. \& Menzies B. K. (1972). Inherent anisotropy in a sand. Géotechnique 22, No. 1, 115-128.

Bathurst, R. J. (1985). A study of stress and anisotropy in idealized granular assemblies. PLd thesis, Queens University, Kingston.

Bolton, M. D. (1984). The strength and dilatancy of sands. Cambridge University Engineering Department publication CUED/D-Soils/TR 152.

Castro, G. (1969). Liquefaction of sand. PhD thesis, Harvard University.

Miura, S., Toki, S. \& Tanizawa, F. (1984). Cone penetration characteristics and its correlation of static and cyclic deformation-strength behaviours of anisotropic sand. Soils Fdns 24, No. 2, 58-74.

Oda, M. (1972a). Initial fabrics and their relations to mechanical properties of granular material. Soils Fdns 12, No. 1, 17-36.

Oda, M. (1972b). The mechanism of fabric changes during compressional deformation of sand. Soils Fdns 12, No. 2, 1-18.
Oda, M., Konishi, J. \& Nemat-Nasser, S. (1980). Some experimentally based fundamental results on the mechanical behaviour of granular materials. Géotechnique 30, No. 4, 479-495.

Rothenburg, L. (1980), Micromechanics of idealized granular systems. PhD thesis, Carleton University, Ottawa.

Rothenburg, L., Jefferies, M. G. \& Matyas, E. L. (1985). Effects of microstructural anisotropy on stress distributions in granular materials. Proc. 10th Canadian Congr. Applied Mechanics, University of Western Ontario.

Rothenburg, L. \& Selvadurai, A. P. S. (1981). A micromechanical definition of the Cauchy stress tensor for particulate media. In Mechanics of structured media, part B, pp. 469-486 (ed. A. P. S. Selvadurai). Amsterdam: Elsevier.

Kowe, P. W. (1971). Theoretical meaning and observation of deformation parameters for soils. Proc. Roscoe Memorial Symp. Stress-Strain Behaviour of Soils, Cambridge, pp. 143-194.

Valanis, K. C. (1971). A theory of viscoplasticity without a yield surface. Archwm Mech. 23, No. 4, 517-535. 